\title{
Laparoscopic Gastrectomy for Gastric Cancer
}

\author{
Hyuk-Joon Lee Han-Kwang Yang \\ Department of Surgery and Cancer Research Institute, Seoul National University College of Medicine, Seoul, Korea
}

\section{Key Words}

Laparoscopic surgery · Gastrectomy · Gastric cancer · Review

\begin{abstract}
Laparoscopic gastrectomy for gastric cancer is rapidly becoming popular because of the technical developments and the accumulated data of laparoscopic surgery in gastric cancer patients. The aim of this review is to present the current body of evidence and to highlight controversial issues of laparoscopic gastrectomy for gastric cancer. Laparoscopic distal gastrectomy (LDG) provides better or comparable outcomes compared to conventional open distal gastrectomy (ODG) in terms of short-term results. The long-term survival of LDG is expected to be comparable to that of ODG in earlystage gastric cancer, and an ongoing Korean multicenter randomized controlled trial (KLASS-01) will provide more clear evidence. Laparoscopic total gastrectomy is still selectively performed compared to LDG, and there is still debate on the safety of the laparoscopic esophagojejunostomy technique. Laparoscopic pylorus-preserving gastrectomy seems to be preferred for early gastric cancer in the middle third of the stomach in terms of functional advantages and comparable oncologic outcome. Evidence for LDG for advanced gastric cancer is still insufficient and the issue of lack of generalization still remains, even after ongoing multicenter randomized controlled trials have revealed clinical evidence. Laparoscopic sentinel node navigation surgery is
\end{abstract}

still experimental and the surgical procedure has yet to be standardized. Robotic gastrectomy is feasible for early gastric cancer in terms of similar outcome, but is much more expensive in comparison to laparoscopic surgery. Its benefit over the conventional laparoscopic gastrectomy has not yet been proven.

Copyright $\odot 2013$ S. Karger AG, Basel

\section{Introduction}

After the initial introduction of laparoscopic gastrectomy for gastric cancer by Kitano et al. [1] in 1993, the procedure has spread rapidly and is now considered one of the standard minimally invasive procedures for the treatment of early gastric cancer (EGC). In Korea, for example, the number of laparoscopic surgeries for gastric cancer increased from 740 in 2004 to 3,783 in 2009, rising from $6.6 \%$ of all gastric cancer surgeries to $25.8 \%$, respectively [2]. The cumulative number of laparoscopic gastric cancer surgeries from 1995 to 2009 was estimated to be 14,731 in Korea [3]. Along with laparoscopic gastrectomy, other laparoscopic gastric surgeries such as wedge resection or peptic ulcer surgery has also increased (fig. 1).

Over last two decades, laparoscopic gastrectomy has provided a lot of clinical evidence, mainly from Korea and Japan, and today some experts have extended their use of laparoscopic gastrectomy from EGC to advanced gastric

\section{KARGER}

E-Mail karger@karger.com

www.karger.com/dsu
(C) 2013 S. Karger AG, Basel

$0253-4886 / 13 / 0302-0132 \$ 38.00 / 0$
Han-Kwang Yang, MD, PhD, FACS

Department of Surgery and Cancer Research Institute Seoul National University College of Medicine 101 Daehang-ro, Jongno-gu, Seoul 110-744 (Korea) E-Mail hkyang@snu.ac.kr 
Fig. 1. Annual number of laparoscopic gastric surgeries in Korea (1995-2008).

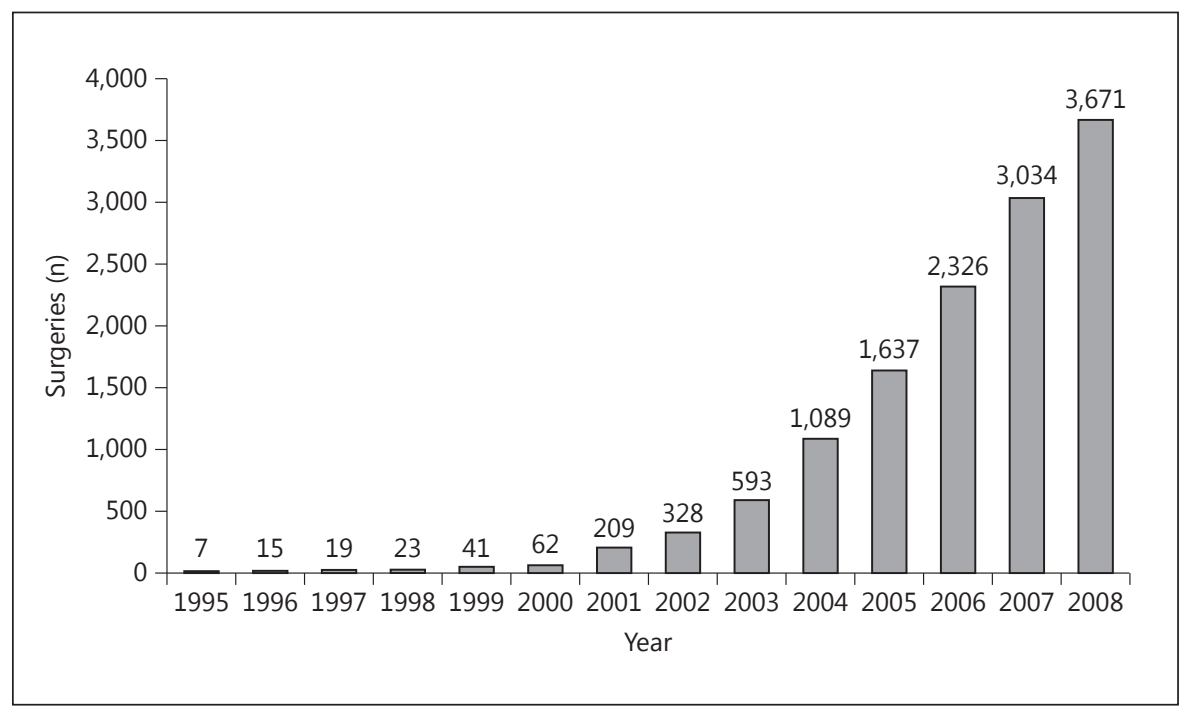

cancer (AGC) due to the accumulated surgical experience and instrumental developments.

For the indication of laparoscopic gastrectomy, gastric adenocarcinoma is commonly indicated; however, benign gastric ulcer or gastric subepithelial tumor is sometimes indicated, too. The extent of lymph node (LN) dissection is an important issue. In general, most articles report $\mathrm{D} 1+\alpha, \mathrm{D} 1+\beta$, or $\mathrm{D} 2$ dissection, which means at least a D1 + LN dissection according to the 3rd Japanese Gastric Cancer Treatment Guidelines [4].

Laparoscopic gastrectomy can be classified into laparoscopic distal gastrectomy (DG), total gastrectomy, pylorus-preserving gastrectomy (PPG), and proximal gastrectomy in terms of the resection extent of the stomach. From the perspective of the surgical approach, it can be also classified into laparoscopy-assisted gastrectomy (LAG) and totally laparoscopic gastrectomy. LAG means parts of the surgical procedures (usually anastomosis) are performed outside the body (extracorporeal) through minilaparotomy. In contrast, totally laparoscopic gastrectomy means all parts are performed inside the body (intracorporeal) by a laparoscopic approach (i.e. intracorporeal anastomosis). Combing these two criteria, dozens of terms are used in the literature, such as laparoscopy-assisted distal gastrectomy (LADG), laparoscopy-assisted total gastrectomy (LATG), (totally) laparoscopic distal gastrectomy (TLDG or LDG), etc. [3]. However, this terminology sometimes overlaps, for example the term 'LADG' is sometimes used for indicating both LADG and TLDG.

Laparoscopic Gastrectomy
In this review, we will present the current clinical data of the different types of laparoscopic gastrectomy in terms of short- and long-term outcomes, with special reference to the extent of resection and indication of surgery. In addition, we will discuss several controversies surrounding laparoscopic gastrectomy and highlight what is still required in the field of laparoscopic gastrectomy for gastric cancer. Finally, laparoscopic sentinel node (SN) navigation surgery and robotic gastrectomy will be discussed. Laparoscopic wedge resection, sometimes included in laparoscopic gastrectomy, will not be covered in this article.

\section{Methods}

A PubMed search was carried out using the search terms 'laparoscopic gastrectomy' AND 'gastric cancer' along with their synonyms or abbreviations until February 2013. Meta-analyses and randomized controlled trials (RCT) were firstly reviewed, and the references of the each identified articles were also evaluated. Largescale prospective cohort studies, retrospective case-control studies, and case series were also reviewed. Selected ongoing clinical trials in which the clinical influence seems to be high were also included.

\section{Laparoscopic Distal Gastrectomy}

LDG or LADG is the first and most commonly performed laparoscopic gastrectomy for gastric cancer. Nowadays, the general indication is considered as EGC 
Table 1. Prospective RCTs comparing LADG vs. ODG

\begin{tabular}{|c|c|c|c|c|c|c|}
\hline & Author & Country & Study period & Sample size (L/O) & LND & Reconstruction \\
\hline 1 & Kitano et al. [12] & Japan & $1998-2001$ & $14 / 14$ & $\mathrm{D} 1+a$ & B-I \\
\hline 2 & Hayashi et al. [13] & Japan & $1999-2001$ & $14 / 14$ & $\mathrm{D} 1+a$ & B-I \\
\hline 4 & Lee et al. [15] & Korea & $2001-2003$ & $24 / 23$ & $\mathrm{D} 2$ & B-I \\
\hline 5 & Kim et al. [16] & Korea & $2003-2005$ & $82 / 82$ & $\mathrm{D} 1+\beta$ or $\mathrm{D} 2$ & B-I \\
\hline 6 & Kim et al. [17] & Korea & $2006-2007$ & $179 / 163$ & $\mathrm{D} 1+\beta$ or $\mathrm{D} 2$ & B-I (mainly) \\
\hline
\end{tabular}

L = Laparoscopic; $\mathrm{O}=$ open; LND = lymph node dissection; B-I = Billroth-I gastroduodenostomy; B-II = Billroth-II gastrojejunostomy; RY = Roux-en-Y gastrojejunostomy.

located in the middle or lower third of the stomach. Three types of reconstruction are usually performed: gastroduodenostomy (Billroth I), loop gastrojejunostomy (Billroth II), and Roux-en-Y gastrojejunostomy.

Most surgeons use 5 or 6 trocars in a similar location for LADG. As usual, the range of LN dissection covers Nos. 1, 3, 4sb, 4d, 5, 6, 7, 8a, 9, and 11p with or without Nos. $12 \mathrm{a}$ and $14 \mathrm{v}$ according to the Japanese gastric cancer classification [5]. For the anastomosis, a circular or linear stapler is commonly used through a 4 - to 5 -cm vertical or transverse minilaparotomy on the upper abdomen in case of extracorporeal gastroduodenostomy or gastrojejunostomy [6]. In case of intracorporeal anastomosis, a deltashaped anastomosis is commonly applied for the gastroduodenostomy [7]. Although intracorporeal anastomosis has some advantages, such as providing a better operative view and a wider range for movement during the reconstruction (especially for obese patients), it is still controversial to use routinely because of its higher cost for more staples and similar clinical outcomes compared with extracorporeal anastomosis [8].

Several meta-analyses focusing on LADG in comparison to open distal gastrectomy (ODG) have been published. Among them, Zeng et al. [9] performed a metaanalysis including 5 RCTs and 18 non-RCTs with 3,411 patients, and reported that LADG may reduce intraoperative blood loss, overall postoperative morbidity, postoperative analgesic consumption, and hospital duration without increasing the total hospitalization costs and cancer recurrence rate. They also reported that the mean number of retrieved LNs and overall survival rate were comparable between the LADG and ODG groups. Similarly, Strong and colleagues [10] reported that LADG can be performed safely with a shorter hospital stay and fewer complications than open surgery in a meta-analysis with 6 RCTs and 19 non-RCTs with 3,055 patients. In addition, Jiang et al. [11] recently made another meta-analysis including 8 RCTs ( $\mathrm{n}=784$ patients) only and reported that LADG has the advantage of better short-term outcome compared to ODG.

At least six important RCTs comparing LADG versus ODG have been published in the English literature [1217] (table 1). Five of these trials were from Japan or Korea, and only one was from a Western country (Italy). The number of patients enrolled in each trial ranged from 28 to 342 . The three reports from Korea [15-17] used adequate random allocation sequences; however, the exact method of randomization was unclear in the other trials, which only stated that allocation had been 'randomized' [11]. Except for the RCT from Italy [14], the trials from the East included only clinically EGC or stage I disease. Only one RCT [17] was conducted as a multicenter trial in a single country, and to date, there have been no multinational trials. The long-term survival difference was not available because of insufficient follow-up time or small sample size in these RCTs.

Among the RCTs, the largest and most noticeable one is the Korean multicenter trial named KLASS (Korean Laparoendoscopic Gastrointestinal Surgery Study; NCT00452751). The indication was clinical stage I (cT1N0M0, cT1N1M0, and cT2N0M0) gastric adenocarcinoma. The primary endpoint was overall survival, and the secondary endpoints were disease-free survival, morbidity, mortality, quality of life, inflammatory and immune responses, and cost-effectiveness. A distal gastrectomy with $\mathrm{D} 1+\beta$ or $\mathrm{D} 2 \mathrm{LN}$ dissection was performed in both groups. Reconstruction was performed by Billroth I or Billroth II or Roux-en-Y fashion, depending on the surgeons' preference. To assure high surgical quality, surgery was performed by 15 surgeons, who had performed 
at least 50 cases each of LADG and ODG, at 12 institutes, which had performed more than 80 cases of distal gastrectomy per year. The initial sample size was 1,400 . From February 2006 to August 2010, 1,415 patients (704 LADG and 711 ODG) were enrolled, and the final results are expected to be reported in September 2015 [18].

The interim analysis of this KLASS-01 trial was published in 2010. A total of 342 patients were randomized (179 LADG and 161 ODG). There were no significant differences between the two groups concerning patient demographics. The postoperative complication rates of LADG and ODG groups were 10.5\% (17/179) and 14.7\% $(24 / 163, \mathrm{p}=0.137)$. The postoperative mortality was $1.1 \%$ $(2 / 179)$ and $0 \%(0 / 163)$ in the LADG and ODG groups $(\mathrm{p}=0.497)$. The authors concluded that there was no significance difference in the morbidity and mortality between the two groups [17].

Another important Korean single-center RCT, conducted by Kim et al. [16], was published in 2008. This study aimed to evaluate the quality of life after LADG compared to ODG ( $\mathrm{n}=82$ in each group) in patients with EGC. The LADG group showed better functional and symptom scales of EORCT QLQ-C30 and QLQ-STO22 at 3 months after surgery. Also, intraoperative blood loss, total amount of postoperative analgesics, and postoperative hospital stay were significantly less in the LADG group. The authors concluded that LADG resulted in improved quality of life outcomes after surgery in EGC patients compared to ODG.

The RCT from Italy was published by Huscher et al. [14] in 2005. This study was unique in terms of inclusion of advanced cancer as well as reporting survival data. Among the 59 patients enrolled, 37 (63\%) were finally revealed as stage II or more. Operative morbidity and mortality rates were 26.7 and $3.3 \%$ in LADG group and 27.6 and $6.7 \%$ in the ODG group, respectively. Five-year overall survival rates were 58.9 and $55.7 \%$ in the LADG and ODG groups. Although the authors concluded that LADG for distal gastric cancer is a feasible and safe oncologic procedure, there was a lot of criticism concerning this trial, including the small number of patients, enrollment of diverse stages, surgical quality, and lack of background data for the inclusion of AGC.

Recently, the Japanese Clinical Oncology Group (JCOG) launched an RCT comparing LADG versus ODG for clinical stage I gastric cancer. This trial (JCOG 0912, UMIN000003319) plans to enroll 920 patients within 5 years. The primary endpoint is overall survival, and the secondary endpoints are relapse-free survival, conversion rate of LADG group, short-term clinical outcomes, and postoperative quality of life [19]. Therefore, the study design of the JCOG 0912 trial is basically the same as the KLASS trial, and these two trials should provide solid evidence for the role of LADG in patients with stage I gastric cancer.

For the long-term outcome of LADG, many case-control studies and case series are currently available [20-23]. The Japanese Laparoscopic Surgery Study Group (JLSSG) reported a retrospective multicenter study of laparoscopic gastrecomy for EGC in 2007. Analyzing 1,294 patients from 16 hospitals from 1994 to 2003, they showed that only $6(0.6 \%)$ patients had a recurrence during a median follow-up of 36 months (range: 13-113), and the 5-year disease-free survival rate was $99.8 \%$ for stage Ia, $98.7 \%$ for stage $\mathrm{Ib}$, and $85.7 \%$ for stage II disease. In this cohort, LADG was performed in 1,185 patients (91.5\%), and the 5-year disease-free survival after LADG was 99.4\% [20].

The KLASS Group also reported a similar retrospective multicenter long-term outcome of 1,417 patients who underwent LAG at 10 hospitals from 1998 to 2005. LADG was performed for 1,263 patients (89.1\%). Recurrence was observed in 1.6\% $(19 / 1,186)$ in EGC and $13.4 \%$ (31/231) in AGC during 41 months of median follow-up (range: 2-109). Recurrence time and pattern was similar to that of conventional open surgery. Thirty-four patients out of $50(68.0 \%)$ had a recurrence within 2 years after surgery, and the recurrence pattern was hematogenous in $17(34.0 \%)$, peritoneal in $11(22.0 \%)$, locoregional in 10 (20.0\%), distant LNs in 2 (4.0\%), and mixed in 10 (20.0\%) [21].

Strong et al. [22] at Memorial Sloan-Kettering Cancer Center in New York reported a retrospective case-control study comparing 30 LADG with 30 ODG. Controls were matched for stage, age, and gender from 2005 to 2008. The mean number of resected LNs was 18 (range: 7-36) in the LADG group and 21 (range: 7-44) in the ODG group $(\mathrm{p}=0.03)$. There were 4 recurrences $(13.3 \%)$ in the LADG group during 11 months of follow-up and 5 recurrences $(16.6 \%)$ in the ODG group during 13.8 months follow-up $(\mathrm{p}=0.71)$. Our group did a similar retrospective case-control study in which the clinical outcomes of EGC patients who underwent LADG $(\mathrm{n}=100)$ and sex-, age-, and BMI-matched EGC patients who underwent ODG $(n=100)$ were compared retrospectively. Although the mean number of resected LNs were smaller in the LADG group compared to the ODG group (29.3 vs. 36.4, $\mathrm{p}<0.001)$, the recurrence rate was not different between the two groups ( $2 \%$ in LADG vs. $1 \%$ in ODG) with no cancer-related deaths for 40 months for LADG and 35 months for ODG [23]. 


\section{Laparoscopic Total Gastectomy}

Unlike LADG, laparoscopic total gastrectomy (LTG) or LATG remains a challenging procedure and the technique has not yet been standardized [24]. The general indication is EGC located in the upper third of the stomach. However, compared to LADG, LATG seems to be selectively performed, even in Korea and Japan. In Korea, for example, $25.3 \%$ (2,354/9,290 patients) of middle or lower third gastric cancer was treated by laparoscopy, but only $7.5 \%$ (231/3,062 patients) of upper third gastric cancer was treated by laparoscopy in 2009 [25].

Trocar placement is similar to LADG; however, many surgeons prefer to place right 2 trocars more medially in LATG for the efficient removal of LNs around the splenic hilum (No. 10), LNs along distal splenic artery (No. 11d), and left paracardial LNs (No. 2).

Esophagojejunostomy is usually made by Roux-en-Y, either with an extracorporeal or intracorporeal approach [3]. Extracorporeal anastomosis is performed through a 4- to $5-\mathrm{cm}$ vertical minilaparotomy incision made on the upper midline. After placing the anvil head into the distal esophagus, the mesentery of the proximal jejunum which was pulled out through the minilaparotomy is divided to make a Roux limb. Thereafter, jejunojejunostomy is made either manually or by a stapler, and finally esophagojejunostomy is performed by a circular stapler. Sometimes, it is difficult to obtain a sufficient proximal resection margin in obese patients or tumors located near the esophagogastric junction, and it is also difficult to get enough length of the Roux limb which is partially exposed through the minilaparotomy site. To overcome these limitations, several types of intracorporeal anastomoses have been developed over the last several years [26].

Transoral introduction of the anvil head of the circular stapler (OrVil) is one of the most promising methods. Sakuramoto et al. [27] reported that intracorporeal esophagojejunostomy with this technique was achieved successfully in 26 out of 27 patients. No other complications, such as hypopharyngeal or esophageal injury, occurred during passage, and no postoperative complications occurred except one anastomotic stenosis. On the other hand, Nagai et al. [28] reported a case series of 94 patients who underwent intracorporeal esophagojejunostomy with a linear stapler. Only 2 cases of anastomotic leakage were developed after surgery, but there was no open conversion or mortality in this cohort.

Recently, a meta-analysis [29] was reported including eight non-RTCs with 314 LTG and 384 open total gastrectomy (OTG) in patients with gastric cancer. LTG showed less intraoperative blood loss, less postoperative complications, and shorter hospital stay compared with OTG, although operation time was longer in the LTG group. Inhospital mortality rates were comparable for LTG (0.9\%) and OTG (1.8\%). The authors concluded that LTG shows better short-term outcomes compared with OTG in patients with gastric cancer. Among eight studies enrolled in this meta-analysis, Kim et al. [30] reported the largest retrospective case-control study in which 73 LTG and 127 OTG were compared. D1+ or D2 LN dissection was performed, and the esophagojejunostomy was in an extracorporeal manner. There were no significant differences in postoperative complication rates. However, LATG could improve time to first flatus, time to commencement of soft diet, administration of analgesics, pain score, and hospital discharge. The KLASS Group also reported a retrospective multicenter cohort study with 131 patients who underwent LATG. Only one patient required conversion to open procedure. The mean number of retrieved LNs was 34.7. The mean duration of postoperative hospital stay was 11.3 days, and the postoperative morbidity rate was $19 \%$ without operative mortality. The most common postoperative morbidity was wound complications at the minilaparotomy site, and there were 3 cases of anastomotic leakage. Six patients (5\%) had recurrence of cancer, and 9 patients (7\%) died during the follow-up period [31].

All of these retrospective data show the safety and effectiveness of LATG; however, a multicenter RCT or prospective cohort study is required to rule out the possibility of publication bias. In Korea, a multicenter single-arm phase II trial evaluating LATG for stage I gastric cancer (KLASS-03) has just been launched. The total number of patients is expected to be 168 , and postoperative 30 -day morbidity and mortality will be primarily measured. The method for anastomosis is not unified and can be determined by the surgeon's preference. To our knowledge, this trial may be the first multicenter trial evaluating LATG in the world, and the final result will reveal the safety issue of LATG in general practice.

\section{Laparoscopic PPG}

According to the Japanese gastric cancer treatment guidelines, PPG can be used for cT1N0 gastric cancer in the middle portion of the stomach with the distal tumor border at least $4 \mathrm{~cm}$ proximal to the pylorus [4]. Therefore, either DG or PPG can be performed to treat middle third EGC. Compared to DG, PPG has several advantages such as nutritional benefit and lower incidence of 
dumping syndrome, bile reflux, and gallstone formation $[32,33]$. Recently, clinical data has been reported that validate the role of PPG done by laparoscopy.

PPG is different from DG in terms of the preservation of the distal antrum (about $3 \mathrm{~cm}$ ), hepatic branch of vagus nerve, right gastric vessel, and infrapyloric vessel. For the LN dissection, the No. 5 and 12a stations remain left and the No. 6 station is partly limited. Gastrogastrostomy is mostly created in an end-to-end manner. In the laparoscopic procedure, it is usually performed using an extracorporeal hand-sewn method since the antrum is too thick to be cut and anastomosed by a linear stapler.

Recently, Hiki and colleagues [34] reported the shortterm outcomes of 307 patients who underwent laparoscopy-assisted pylorus-preserving gastrectomy (LAPPG) from 2005 to 2009. The mean operation time for LAPPG was $229.4 \mathrm{~min}$ and estimated blood loss was $49.1 \mathrm{ml}$. The mean number of dissected LNs was 31.6. Complications developed in 53 patients (17.3\%), and major complications (grade IIIa or higher according to the Clavien-Dindo classification [35]) were observed in only 4 patients (1.3\%). The most frequent complication was gastric stasis, occurring in 19 patients (6.2\%). Body mass index (BMI) was related to the severity of the complications.

Our group performed a retrospective analysis comparing those who underwent LAPPG $(\mathrm{n}=116)$ and LADG $(\mathrm{n}=176)$ for middle third EGC. The overall postoperative morbidity rate was similar between the two groups, although delayed gastric emptying was more frequent in LAPPG than in LADG (7.8 vs. $1.7 \%)$. The number of retrieved LNs was not significantly different (35.9 in LAPPG vs. 35.2 in LADG), and 3-year recurrence-free survival rates were also similar between LAPPG and LADG (98.2 vs. 98.8\%). Serum protein and albumin at postoperative 1 and 6 months as well as abdominal fat area measured by CT scan at postoperative 1 year were significantly less decreased in LAPPG. The 3-year cumulative incidence of gallstone was also significantly lower in LAPPG than in LADG (0 vs. 6.5\%) [36]. Therefore, LAPPG can be considered as a better treatment option than LADG in terms of nutritional advantage and lower incidence of gallstone for middle third EGC.

\section{Risk Factors for Postoperative Morbidity in Laparoscopic Gastrectomy}

Risk factors for postoperative morbidity in laparoscopic gastrectomy may not differ so much from those in open gastrectomy. Three aspects may be considered for

Laparoscopic Gastrectomy the prediction of complication: tumor-related factors, patient-related factors, and surgeon-related factors.

Before starting the KLASS trial, the Korean surgeons had collected large-scale retrospective multicenter data from each participating surgeon's beginning to the end of 2005 to reveal the safety profile and the risk factors for operative morbidity in laparoscopic gastrectomy. The data of 1,485 patients who underwent LAG for gastric cancer with more than D1 LN dissection by 10 surgeons were analyzed. Overall morbidity and mortality rates were 14.0 and $0.6 \%$, respectively. Complications included wound problems $(4.2 \%, \mathrm{n}=62)$, intraluminal bleeding $(1.3 \%, \mathrm{n}=20)$, intra-abdominal abscess or fluid collection $(1.3 \%, \mathrm{n}=19)$, anastomotic leakage $(1.3 \%, \mathrm{n}=18)$, and intra-abdominal bleeding $(1.3 \%, \mathrm{n}=18)$. Sex, comorbidity, type of resection, and surgeon's experience were found to be independent risk factors for local complications, and age was found as an independent risk factor for systemic complication [37]. Furthermore, among various comorbidities of the patients, pulmonary comorbidity was shown to be related with most types of immediate postoperative complications compared with other comorbidities [38].

The KLASS group also performed several comparative studies in terms of several interesting potential risk factors for complication, such as age, obesity, surgeon's inexperience, etc. In terms of age, laparoscopic surgery is generally regarded as offering a substantial advantage to old patients in terms of fewer cardiorespiratory complications, shorter hospital stay, and faster return to physical activities [39]. Cho et al. [40] reported that patients aged 70 years or more $(n=226)$ did not show significant differences in postoperative morbidity or mortality, compared to patients aged 45-69 years $(n=890)$. Preoperative comorbidity was revealed as the only risk factor for postoperative complications in this elderly group.

Obesity is known to be one of the risk factors for postoperative morbidity [41]. However, there are conflicting reports suggesting that obesity may or may not increase operative morbidity following laparoscopic gastrectomy $[42,43]$. Lee et al. [44] compared clinical outcomes between high BMI $(\geq 25, \mathrm{n}=432)$ and low BMI $(<25, \mathrm{n}=$ $1,053)$. Postoperative morbidity and mortality did not differ between the high BMI (15.7 and 0.9\%) and low BMI (14 and $0.5 \%$ ) groups. Only the operation time and the number of retrieved LNs were significantly different between the high BMI (242.5 min and 30.4) and low BMI (223.7 min and 32.6) groups, especially for male patients undergoing surgery by surgeons who had performed 40 or fewer LAGs. The authors concluded that although high 
BMI itself did not increase operative morbidity, a careful approach is required for male patients with high BMI when a surgeon is relatively inexperienced with LAG.

\section{Laparoscopic Gastrectomy for Advanced Cancer}

As surgical experience increases, some surgeons are now applying laparoscopic gastrectomy with D2 LN dissection for patients with AGC. There have been reports of short-term outcomes with morbidity rates of 11.3$15.9 \%$ and mortality rates of $0.8-2.2 \%$, which are comparable to those of open surgery [2].

A recent meta-analysis, including seven case-control studies with 1,271 AGC patients (626 LADG and 645 ODG), showed that LADG patients had longer operative time but less estimated blood loss, less analgesic requirement, and a shorter hospital stay compared with patients undergoing ODG. There were no significant differences between the two groups in number of LN dissections, postoperative mortality, overall complications, and 3year overall survival rate. Therefore, the authors concluded that the oncologic outcomes of LADG for AGC patients were comparable with an open approach [45].

Kim and colleagues [46] reported the short-term outcomes of a prospective single-arm phase II trial evaluating the feasibility of laparoscopic gastrectomy for patients with cT2N0-cT4aN2 gastric cancer (NCT01441336). Of the 157 patients enrolled, conversion to open surgery occurred in 11 patients $(7.0 \%)$. The mean number of retrieved LNs was 52.7 for distal gastrectomy and 63.8 for total gastrectomy. The total complication rate was $25.5 \%$ as a whole, and the local and systemic complication rates of grade II or higher according to the Clavien-Dindo classification were 8.3 and $3.2 \%$. One patient died of operative complications. They concluded that laparoscopic gastrectomy with D2 LN dissection was safe and technically feasible for the treatment of AGC, with an acceptable rate of morbidity and mortality.

Along with these background data of LADG on AGC, another KLASS trial evaluating the efficacy of LADG with D2 LN dissection for cT2-T4a/cN0-N1 gastric cancer (KLASS-02-RCT) was launched in October 2011 (NCT01456598). The estimated sample size is 1,050 and the primary endpoint is 3 -year disease-free survival rate (fig. 2). As the surgical quality may become one of the most important issues in this clinical trial, surgeons are required to be standardized and qualified by participating in a surgical quality control trial, entitled 'KLASS-02-QC: Standardization of D2 Lymphadenectomy and Surgical
Quality Control for KLASS-02 Trial' (NCT01283893). Each applicant should submit three unedited videos each for LADG and ODG, respectively, which are to be evaluated by independent reviewers [2]. As a result, only certified surgeons can join KLASS-02-RCT. On February 2013, 18 surgeons at 11 institutes had been qualified, and 316 patients out of $1,050(30.1 \%)$ were enrolled for the last year.

A Japanese group also started another multicenter phase II/III trial evaluating LADG with D2 LN dissection for CT2-T4a gastric cancer. After accrual of 180 patients, of which 90 are to be treated with the laparoscopic approach, the incidence of major surgical complications will be assessed. If an early-stopping rule because of high incidence of complications does not apply, the trial will continue accrual for a total of 500 patients to show noninferiority of the laparoscopic approach [24]. These two Korean and Japanese clinical trials are expected to reveal the role of laparoscopic surgery for AGC, although the generalization issue will still remain.

\section{Laparoscopic SN Node Navigation Surgery}

Several experimental studies have shown that SN biopsy with radioisotope and/or visible dye could be feasible for EGC in open and laparoscopic surgery [47-49]. However, because of unsatisfactory sensitivity and heterogeneity of SN biopsy among practicing surgeons, the concern and limitation about its clinical application still exists.

A recent meta-analysis evaluating 38 studies with 2,128 patients showed that the pooled SN identification rate, sensitivity, negative predictive value, and accuracy were 93.7, 76.9, 90.3, and 92.0\%, respectively. Subgroup analysis showed that early $\mathrm{T}$ stage, combined tracers, submucosal injection method, conventional open surgery, and usage of immunohistochemistry were associated with a higher $\mathrm{SN}$ identification rate and sensitivity. Focusing on surgical procedure, SN identification rate, sensitivity, false-negative rate, and accuracy in the laparoscopic group (11 studies) and open group (29 studies) were 89.3 vs. $95.0 \%, 68.6$ vs. $78.3 \%, 31.4$ vs. $21.7 \%$, and 92.6 vs. $91.9 \%$, respectively [50].

Therefore, considering its fatal outcome of false-negative results on $\mathrm{SN}$ navigation surgery for the patients with EGC, further studies are needed to confirm the best procedure and standard criteria, especially in laparoscopic surgery [51]. 
Fig. 2. Diagram of a RCT comparing LADG vs. ODG for AGC (KLASS-02-RCT). pm = Proper muscle; $\mathrm{FU}=$ follow-up; $\mathrm{PP}=$ per protocol.

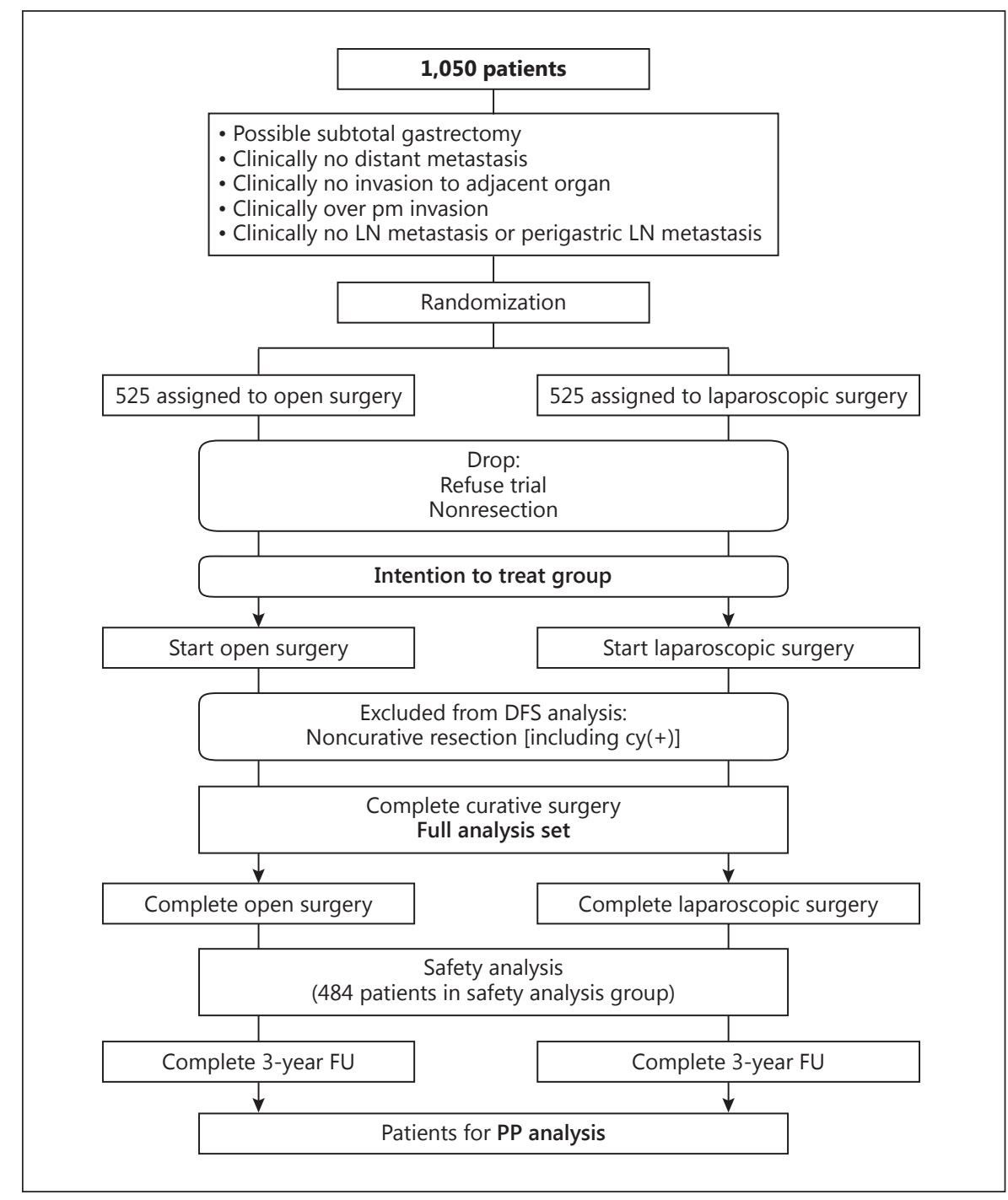

\section{Robotic Surgery}

Robot-assisted surgery is laparoscopic surgery using robotic instruments. Compared to the laparoscopic surgery, robotic surgery may have some benefits such as three-dimensional imaging, increased degree of freedom, a steady camera platform, and the filtration of resting tremor. Several reports about robotic surgery for gastric cancer have been reported, mainly from institutes in Korea $[52,53]$. These reports suggest comparable short-term morbidity and oncologic outcomes compared with laparoscopic gastrectomy. However, the concrete advantage of robotic surgery for the patient still remains elusive in terms of the similar number of trocars used, longer operation time, negligible difference in blood loss, and much higher cost, even though robotic instruments may provide some benefit of dexterity which has not been proven scientifically [54, 55], especially the ultrasonic shears which do not articulate. Furthermore, there is an energy device in development with roticulating function which may provide an advantage in more demanding tissue dissection at splenic artery or splenic hilum.

To explore the role of robotic gastrectomy for gastric cancer, the Korean Robot Gastrectomy Study Group of KLASS started in 2010 to conduct a multicenter prospective, case-matched clinical trial comparing robotic versus laparoscopic gastrectomy for EGC. Enrollment of $400 \mathrm{pa}-$ tients (200 in each group) was finished in 2012, and surgical complications, quality of life, immunologic response, and cost-effectiveness will be analyzed. 


\section{Conclusion}

Laparoscopic gastrectomy is a promising minimally invasive surgery for gastric cancer that has become popular and standardized. LADG shows better or comparable outcomes compared to ODG in terms of short-term results. The long-term outcome after LADG may be comparable to ODG in EGC, and ongoing Korean and Japanese muticenter RCTs will provide more clear evidence. Data on LATG are still limited, and the stable laparoscopic anastomosis technique is still under debate. LAPPG seems to be optimistic for EGC located in the middle third of the stomach in terms of preservation of function and comparable oncologic outcome.

The clinical body of evidence concerning LADG for AGC is still insufficient, and the lack of generalization still remains an issue even after ongoing Korean multicenter RCTs have provided clinical evidence. Laparoscopic SN navigation surgery seems to be experimental and the surgical procedure has yet to be standardized. Robotic gastrectomy is feasible for EGC in terms of similar outcome, but is associated with much higher cost compared to laparoscopic surgery. Its benefit over the conventional laparoscopic gastrectomy has not been proven.

\section{References}

-1 Kitano S, Iso Y, Moriyama M, Sugimachi K Laparoscopy-assisted Billroth I gastrectomy. Surg Laparosc Endosc 1994;4:146-148.

-2 Yang HK, Suh YS, Lee HJ: Minimally invasive approaches for gastric cancer-Korean experience. J Surg Oncol 2013;107:277-281.

3 Kitano S, Yang HK (eds): Laparoscopic Gastrectomy for Cancer - Standard Techniques and Clinical Evidences. Tokyo, Springer, 2012.

-4 Japanese Gastric Cancer Association: Japanese gastric cancer treatment guidelines 2010 (ver. 3). Gastric Cancer 2011;14:113-123.

5 Japanese Gastric Cancer Association: Japanese classification of gastric carcinoma: 3rd English edition. Gastric Cancer 2011;14:101112 .

-6 Lee HJ, Shiraishi N, Kim HH, Hiki N, Uyama I, Choi SH, Yang HK, Kitano S: Standard of practice on laparoscopic gastric cancer surgery in Korea and Japan: experts' survey. Asian J Endosc Surg 2012;5:5-11.

$>7$ Kanaya S, Kawamura Y, Kawada H, Iwasaki H, Gomi T, Satoh S, Uyama I: The deltashaped anastomosis in laparoscopic distal gastrectomy: analysis of the initial 100 consecutive procedures of intracorporeal gastroduodenostomy. Gastric Cancer 2011;14:365371.

>8 Song KY, Park CH, Kang HC, Kim JJ, Park SM, Jun KH, Chin HM, Hur H: Is totally laparoscopic gastrectomy less invasive than laparoscopy-assisted gastrectomy?: prospective, multicenter study. J Gastrointest Surg 2008 12:1015-1021.

$\checkmark 9$ Zeng YK, Yang ZL, Peng JS, Lin HS, Cai L: Laparoscopy-assisted versus open distal gastrectomy for early gastric cancer: evidence from randomized and nonrandomized clinical trials. Ann Surg 2012;256:39-52.

10 Viñuela EF, Gonen M, Brennan MF, Coit DG, Strong VE: Laparoscopic versus open dista gastrectomy for gastric cancer: a meta-analysis of randomized controlled trials and highquality nonrandomized studies. Ann Surg 2012;255:446-456.
11 Jiang L, Yang KH, Guan QL, Cao N, Chen Y, Zhao P, Chen YL, Yao L: Laparoscopy-assisted gastrectomy versus open gastrectomy for resectable gastric cancer: an update meta-analysis based on randomized controlled trials. Surg Endosc 2013, E-pub ahead of print.

12 Kitano S, Shiraishi N, Fujii K, Yasuda K, Inomata M, Adachi Y: A randomized controlled trial comparing open vs laparoscopy-assisted distal gastrectomy for the treatment of early gastric cancer: an interim report. Surgery 2002;131:S306-S311.

-13 Hayashi H, Ochiai T, Shimada H, Gunji Y: Prospective randomized study of open versus laparoscopy-assisted distal gastrectomy with extraperigastric lymph node dissection for early gastric cancer. Surg Endosc 2005; 19: 1172-1176.

14 Huscher CG, Mingoli A, Sgarzini G, Sansonetti A, Di Paola M, Recher A, Ponzano C: Laparoscopic versus open subtotal gastrectomy for distal gastric cancer: five-year results of a randomized prospective trial. Ann Surg 2005;241:232-237.

15 Lee JH, Han HS, Lee JH: A prospective randomized study comparing open vs laparoscopy-assisted distal gastrectomy in early gastric cancer: early results. Surg Endosc 2005;19: 168-173.

16 Kim YW, Baik YH, Yun YH, Nam BH, Kim DH, Choi IJ, Bae JM: Improved quality of life outcomes after laparoscopy-assisted distal gastrectomy for early gastric cancer: results of a prospective randomized clinical trial. Ann Surg 2008;248:721-727.

17 Kim HH, Hyung WJ, Cho GS, Kim MC, Han SU, Kim W, Ryu SW, Lee HJ, Song KY: Morbidity and mortality of laparoscopic gastrectomy versus open gastrectomy for gastric cancer: an interim report - a phase III multicenter, prospective, randomized trial (KLASS Trial). Ann Surg 2010;251:417-420.

$>18$ Kim HH, Han SU, Kim MC, Hyung WJ, Kim W, Lee HJ, Ryu SW, Cho GS, Kim CY, Yang
HK, Park DJ, Song KY, Lee SI, Ryu SY, Lee JH, Korean Laparoscopic Gastrointestinal Surgery Study (KLASS) Group: Prospective randomized controlled trial (phase III) to comparing laparoscopic distal gastrectomy with open distal gastrectomy for gastric adenocarcinoma (KLASS 01). J Korean Surg Soc 2013; 84:123-130.

19 Nakamura K, Katai H, Mizusawa J, Yoshikawa T, Ando M, Terashima M, Ito S, Takagi M, Takagane A, Ninomiya M, Fukushima N, Sasako M: A phase III study of laparoscopy-assisted versus open distal gastrectomy with nodal dissection for clinical stage IA/IB gastric cancer (JCOG0912). Jpn J Clin Oncol 2013;43:324-327.

20 Kitano S, Shiraishi N, Uyama I, Sugihara K, Tanigawa N, Japanese Laparoscopic Surgery Study Group: A multicenter study on oncologic outcome of laparoscopic gastrectomy for early cancer in Japan. Ann Surg 2007;245: 68-72.

21 Song J, Lee HJ, Cho GS, Han SU, Kim MC, Ryu SW, Kim W, Song KY, Kim HH, Hyung WJ, Korean Laparoscopic Gastrointestinal Surgery Study (KLASS) Group: Recurrence following laparoscopy-assisted gastrectomy for gastric cancer: a multicenter retrospective analysis of 1,417 patients. Ann Surg Oncol 2010;17:1777-1786.

22 Strong VE, Devaud N, Allen PJ, Gonen M, Brennan MF, Coit D: Laparoscopic versus open subtotal gastrectomy for adenocarcinoma: a case-control study. Ann Surg Oncol 2009; 16:1507-1513.

23 Han JH, Lee HJ, Suh YS, Han DS, Kong SH, Yang HK: Laparoscopy-assisted distal gastrectomy compared to open distal gastrectomy in early gastric cancer. Dig Surg 2011;28: 245-251.

24 Kodera Y, Fujiwara M, Ohashi N, Nakayama G, Koike M, Morita S, Nakao A: Laparoscopic surgery for gastric cancer: a collective review with meta-analysis of randomized trials. J Am Coll Surg 2010;211:677-686. 
25 Jeong O, Park YK: Clinicopathological features and surgical treatment of gastric cancer in South Korea: the results of 2009 nationwide survey on surgically treated gastric cancer patients. J Gastric Cancer 2011;11:69-77.

-26 Shim JH, Yoo HM, Oh SI, Nam MJ, Jeon HM, Park CH, Song KY: Various types of intracorporeal esophagojejunostomy after laparoscopic total gastrectomy for gastric cancer. Gastric Cancer 2012, E-pub ahead of print.

-27 Sakuramoto S, Kikuchi S, Futawatari N, Moriya H, Katada N, Yamashita K, Watanabe $\mathrm{M}$ : Technique of esophagojejunostomy using transoral placement of the pretilted anvil head after laparoscopic gastrectomy for gastric cancer. Surgery 2010;147:742-747.

-28 Nagai E, Ohuchida K, Nakata K, Miyasaka Y, Maeyama R, Toma H, Shimizu S, Tanaka M: Feasibility and safety of intracorporeal esophagojejunostomy after laparoscopic total gastrectomy: inverted T-shaped anastomosis using linear staplers. Surgery 2013;153:732-738.

-29 Haverkamp L, Weijs TJ, van der Sluis PC, van der Tweel I, Ruurda JP, van Hillegersberg R: Laparoscopic total gastrectomy versus open total gastrectomy for cancer: a systematic review and meta-analysis. Surg Endosc 2013;27: 1509-1520.

- 30 Kim MG, Kim BS, Kim TH, Kim KC, Yook JH, Kim BS: The effects of laparoscopic assisted total gastrectomy on surgical outcomes in the treatment of gastric cancer. J Korean Surg Soc 2011;80:245-250.

- 31 Jeong GA, Cho GS, Kim HH, Lee HJ, Ryu SW, Song KY: Laparoscopy-assisted total gastrectomy for gastric cancer: a multicenter retrospective analysis. Surgery 2009;146:469-474.

- 32 Isozaki $\mathrm{H}$, Okajima K, Momura E, Ichinona T, Fujii K, Izumi N, Takeda Y: Postoperative evaluation of pylorus-preserving gastrectomy for early gastric cancer. Br J Surg 1996;83: 266-269.

-33 Park DJ, Lee HJ, Jung HC, Kim WH, Lee KU, Yang HK: Clinical outcome of pylorus-preserving gastrectomy in gastric cancer in comparison with conventional distal gastrectomy with Billroth I anastomosis. World J Surg 2008;32:1029-1036.

-34 Jiang X, Hiki N, Nunobe S, Fukunaga T, Kumagai K, Nohara K, Sano T, Yamaguchi T: Postoperative outcomes and complications after laparoscopy-assisted pylorus-preserving gastrectomy for early gastric cancer. Ann Surg 2011;253:928-933.
35 Dindo D, Demartines N, Clavien PA: Classification of surgical complications: a new proposal with evaluation in a cohort of $6336 \mathrm{pa}-$ tients and results of a survey. Ann Surg 2004; 240:205-213.

36 Suh YS, Han DS, Kong SH, Kwon S, Shin CI, Kim WH, Kim HH, Lee HJ, Yang HK: Laparoscopy-assisted pylorus-preserving gastrectomy is better than laparoscopy-assisted distal gastrectomy for middle-third early gastric cancer. Ann Surg 2013, E-pub ahead of print.

37 Kim MC, Kim W, Kim HH, Ryu SW, Ryu SY, Song KY, Lee HJ, Cho GS, Han SU, Hyung WJ, Korean Laparoscopic Gastrointestinal Surgery Study (KLASS) Group: Risk factors associated with complication following laparoscopy-assisted gastrectomy for gastric cancer: a large-scale Korean multicenter study. Ann Surg Oncol 2008; 15:2692-2700.

- 38 Kim W, Song KY, Lee HJ, Han SU, Hyung WJ, Cho GS: The impact of comorbidity on surgical outcomes in laparoscopy-assisted distal gastrectomy: a retrospective analysis of multicenter results. Ann Surg 2008;248:793-799.

39 Koeda K, Nishizuka S, Wakabayashi G: Minimally invasive surgery for gastric cancer: the future standard of care. World J Surg 2011;35: 1469-1477.

40 Cho GS, Kim W, Kim HH, Ryu SW, Kim MC, Ryu SY: Multicentre study of the safety of laparoscopic subtotal gastrectomy for gastric cancer in the elderly. Br J Surg 2009;96:14371442 .

41 Lee JH, Paik YH, Lee JS, Ryu KW, Kim CG, Park SR, Kim YW, Kook MC, Nam BH, Bae JM: Abdominal shape of gastric cancer patients influences short-term surgical outcomes. Ann Surg Oncol 2007;14:1288-1294.

42 Noshiro H, Shimizu S, Nagai E, Ohuchida K, Tanaka M: Laparoscopy-assisted distal gastrectomy for early gastric cancer: is it beneficial for patients of heavier weight? Ann Surg 2003;238:680-685.

43 Ohno T, Mochiki E, Ando H, Ogawa A, Yanai M, Toyomasu Y, Ogata K, Aihara R, Asao T, Kuwano H: The benefits of laparoscopically assisted distal gastrectomy for obese patients. Surg Endosc 2010;24:2770-2775.

44 Lee HJ, Kim HH, Kim MC, Ryu SY, Kim W, Song KY, Cho GS, Han SU, Hyung WJ, Ryu SW, Korean Laparoscopic Gastrointestinal Surgery Study Group: The impact of a high body mass index on laparoscopy assisted gastrectomy for gastric cancer. Surg Endosc 2009;23:2473-2479.
45 Qiu J, Pankaj P, Jiang H, Zeng Y, Wu H: Laparoscopy versus open distal gastrectomy for advanced gastric cancer: a systematic review and meta-analysis. Surg Laparosc Endosc Percutan Tech 2013;23:1-7.

46 Lee JH, Son SY, Lee CM, Ahn SH, Park DJ, Kim HH: Morbidity and mortality after laparoscopic gastrectomy for advanced gastric cancer: results of a phase II clinical trial. Surg Endosc 2013, E-pub ahead of print.

47 Lee JH, Ryu KW, Kim CG, Kim SK, Lee JS, Kook MC, Choi IJ, Kim YW, Chang HJ, Bae JM: Sentinel node biopsy using dye and isotope double tracers in early gastric cancer. Ann Surg Oncol 2006;13:1168-1174.

48 Tajima Y, Yamazaki K, Masuda Y, Kato M, Yasuda D, Aoki T, Kato T, Murakami M, Miwa M, Kusano M: Sentinel node mapping guided by indocyanine green fluorescence imaging in gastric cancer. Ann Surg 2009;249: 58-62.

49 Park DJ, Kim HH, Park YS, Lee HS, Lee WW, Lee HJ, Yang HK: Simultaneous indocyanine green and $(99 \mathrm{~m}) \mathrm{Tc}$-antimony sulfur colloidguided laparoscopic sentinel basin dissection for gastric cancer. Ann Surg Oncol 2011;18: 160-165.

50 Wang Z, Dong ZY, Chen JQ, Liu JL: Diagnostic value of sentinel lymph node biopsy in gastric cancer: a meta-analysis. Ann Surg Oncol 2012;19:1541-1550.

51 Yang HK: Sentinel node biopsy in early gastric cancer: constant exertion for clinical application. Ann Surg Oncol 2012;19:353-354.

52 Song J, Oh SJ, Kang WH, Hyung WJ, Choi SH, Noh SH: Robot-assisted gastrectomy with lymph node dissection for gastric cancer: lessons learned from an initial 100 consecutive procedures. Ann Surg 2009;249:927-932.

53 Yoon HM, Kim YW, Lee JH, Ryu KW, Eom BW, Park JY, Choi IJ, Kim CG, Lee JY, Cho SJ, Rho JY: Robot-assisted total gastrectomy is comparable with laparoscopically assisted total gastrectomy for early gastric cancer. Surg Endosc 2012;26:1377-1381.

54 Wall J, Marescaux J: Robotic gastrectomy is safe and feasible, but real benefits remain elusive. Arch Surg 2011;146:1092.

55 Park JY, Jo MJ, Nam BH, Kim Y, Eom BW, Yoon HM, Ryu KW, Kim YW, Lee JH: Surgical stress after robot-assisted distal gastrectomy and its economic implications. Br J Surg 2012;99:1554-1561. 